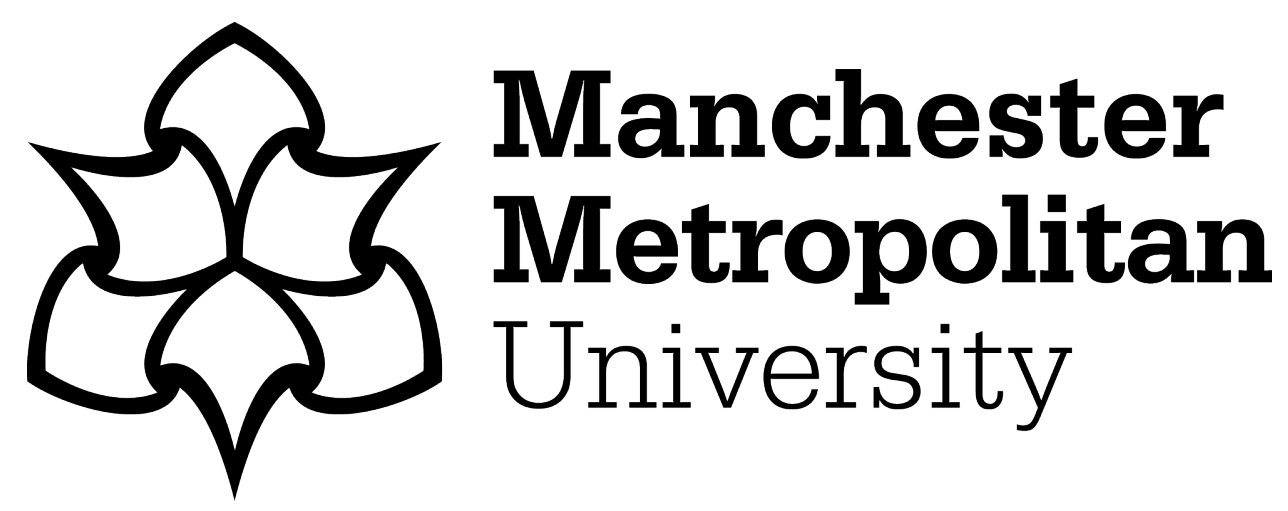

Tom Dieck, D, tom Dieck, MC, Moorhouse, N and Jung, T (2018) Tourists' Virtual Reality Adoption: An Exploratory Study from Lake District National Park. Leisure Studies, 37 (4). pp. 371-383. ISSN 0261-4367

Downloaded from: https://e-space.mmu.ac.uk/620363/

Version: Accepted Version

Publisher: Taylor \& Francis (Routledge)

DOI: https://doi.org/10.1080/02614367.2018.1466905

Please cite the published version 
Please cite as following: tom Dieck, D., tom Dieck, M.C., Moorhouse, N \& Jung, T. (2018). Tourists' Virtual Reality Adoption: An Exploratory Study from Lake District National Park, Leisure Studies, Forthcoming.

\title{
Tourists' Virtual Reality Adoption: An Exploratory Study from Lake District National Park
}

\begin{abstract}
Virtual reality (VR) transforms the way destinations market their tourism offerings. To fully understand the opportunities of a technology, initial research is required assessing user adoption. However, empirical research and particularly exploratory qualitative research on VR adoption in tourism context is limited. Therefore, this study uses an exploratory interview approach with 35 participants near Lake District National Park, UK. Using thematic analysis, this study explores factors that influence VR adoption as well as the influencing factors on tourists' behavioural intentions. This study adds to academia by qualitatively exploring the adoption of a scarcely researched technology within the tourism context.
\end{abstract}

Keywords: Virtual reality, adoption, tourism, Lake District

\section{Introduction}

Information communication technologies (ICTs) are at the forefront of influencing how people consume products or services. According to Zorn et al. (2012, p. 329), traditional leisure activities include "reading, gardening and travel ... [and] the Internet and other ICTs alter how people spend their leisure time. In particular, travel is one of the leisure industries that is deeply affected by technological changes (tom Dieck et al., 2017). Online review sites (Niu et al., 2016), social media networks (Narangajavana et al., 2017) and augmented reality (AR) (Hassan et al., 2017; tom Dieck \& Jung, 2017; Tussyadiah et al., 2017a) have all been thoroughly investigated as part of the tourism and leisure literature. Fully immersive Virtual Reality (VR) applications are at the forefront of interactive tourism experiences however, research within the tourism and leisure context to date is scarce. VR allows users to fully immerse themselves in a digital world. The majority of applications exist in the gaming context (Rauschnabel et al., 2017) however, increasing interest on its opportunities is placed in the tourism and leisure industry. Museums, theme parks and sport events are just few sectors within the leisure industry where VR applications have successfully been implemented in order to provide enhanced experience. Nevertheless, especially its opportunities in the context of National Park is not fully explored yet.

In order to fully understand the opportunities of technology, initial research is required assessing user adoption and intention to accept or reject technologies which is particularly important in the early stages of diffusion (Rauschnabel \& Ro, 2016). To date, there has been a wide stream of technology adoption research, most notably starting with the technology acceptance model (TAM) by Davis in 1989 within the information 
systems context. Since then, more recent theories adopted the initial ideas of the TAM and further developed it to accommodate more hedonic related variables which become increasingly important due to the interactive and social nature of latest technologies. Examples of such theories include Uses and Gratification Theory (U\&GT), Unified Theory of Acceptance and Use of Technology (UTAUT) or Flow Theory (Rauschnabel et al., 2017). Ayeh et al. (2013) revealed that as part of technology adoption research, it is essential to explore context-specific variables in order to enhance the explanatory power of technology adoption models. Interestingly, the majority of studies remain of quantitative nature and simply test existing correlations, contributing to the gap in the technology adoption literature.

$\mathrm{AR}$ is a similar context, and previous studies chose to study the adoption of $\mathrm{AR}$, revealing factors to influence the behavioural intentions which were different for the use of AR as travel guides (Kourouthanassis et al., 2015) or as mobile AR within the cultural heritage context (tom Dieck \& Jung, 2015). This shows that adoption research is casespecific and how factors need to be explored for specific contexts (Ayeh et al., 2013). Recently, this has been supported by Kalantari (2017), who conducted a comprehensive literature review on consumers' adoption of wearable technologies. Consequently, it can be argued that empirical research and particularly exploratory qualitative research on VR adoption is limited. Therefore, this study aims to answer the following research questions (RQs):

RQ1: Which factors drive tourists' VR adoption within the national park context?

RQ2: How is VR influencing tourists' behavioural intentions within the national park context?

The Lake District National Park is hereby taken as context as it recently was one of the first national parks to develop and implement a VR application to provide potential tourists with a virtual flight over the landscape. Consequently, it was perceived a strong case for exploring how VR can be adopted.

\section{Literature Review}

\section{Virtual reality in tourism}

VR has been anticipated in tourism literature for over a decade (e.g. Hobson and Williams, 1995) and is set to significantly impact tourism marketing (Disztinger et al., 2017). It provides marketers with opportunities to communicate with the intended market by offering a rich and immersive experience for potential tourists to explore tourism destinations prior to visiting (Huang et al., 2016). An example is travel agents that may integrate VR in-store to persuade potential tourists to step inside and preview tourism offerings such as destinations and accommodation, and essentially make bookings (Whyte, 2016). According to Guttentag (2010), VR is effective because it provides extensive sensory information to prospective tourists - a factor particularly suitable for the tourism industry given the intangibility of the tourism product. As users are immersed in the head mounted display (HMD), they are almost entirely isolated from the outside world which intensifies the virtual experience and perception of presence within the virtual environment (Disztinger et al., 2016). Previous research suggests that aesthetically 
pleasing content that highlights distinct attractions or presents the destination in creative ways will likely prompt a higher level of arousal (Tussyadiah et al., 2016; Huang et al., 2016). Multisensory cues (e.g. sound and visuals combined) are important to achieve a high level of presence in the virtual environment (Martins et al. 2017; Jung et al. 2017), and more complete absorption leads to increased enjoyment and generates positive attitudes toward the destination (Tussyadiah et al., 2016). The closer to reality the system is, the greater the VR's effectiveness as a marketing tool (Martins et al., 2017). In the tourism sector, VR experiences have been considered promising and capable of generating emotional connections between tourists and destinations (Huang et al. 2013; Griffin et al. 2017). This 'try before you buy' experience provides potential tourists with new knowledge and perspectives of a destination which will likely influence behavioural intentions and encourage physical visitation and word of mouth recommendation, and consequently, increase visitor number and local business demand at the destination (Tussyadiah et al., 2017b; Jung et al., 2017). However, further investigation into VR's usefulness and enjoyment factors are essential for the technology to achieve mass-market consumption (Disztinger et al., 2017).

\section{State of the art in technology adoption}

Technology adoption is an important area of research as it indicates the diffusion of technological innovations (Rauschnabel \& Ro, 2016). It provides implications on what technology, features and developments are accepted and rejected by users, ultimately influencing the success of technological implementations (tom Dieck et al., 2017). Early technology adoption research dates back to the Diffusion of Innovation theory (DIT) by Rogers (1962) which focused on the innovation decision process and considered factors such as relative advantage, compatibility, complexity, trialability and observability as part of users' decision to accept or reject an innovation. This was later followed by the Flow Theory (Czikszentmilhalyi, 1975) which developed the concept of the optimal experience incorporating ideas of concentration, playfulness and perceived control into the adoption of innovations. In the same year, Fishbein and Ajzen (1975) proposed the Theory of Reasoned Action (TRA), the first theory that looked at behavioural intention to use innovations influenced by behavioural beliefs and subjective norms. Later, Ajzen (1985) added Czikszentmilhalyi's idea of behavioural control into the adopted Theory of Planned Behaviour (TPB). These developments show the progression of technology adoption research over time. Nevertheless, the first fully applicable technology-related adoption model, TAM, came in 1989, when Davis proposed that the perceived ease of use and perceived usefulness drive users' behavioural intention to adapt and actual use a technology. Since then, there has been a wide stream of research applying and modifying the TAM into various contexts. Within tourism and leisure literature, a wide number of studies merged theories such as Flow, TAM and TPB (Chung et al., 2015; Jung et al., 2014; tom Dieck et al., 2017). However, especially with the increase in consumer technologies, with a focus on hedonic features, more research looked at factors such as gratification in order to explain the adoption behaviour (Rauschnabel et al., 2017). According to Kalantari and Rauschnabel (2017), perceived benefits of utilising a technology are generally expected to drive consumers' adoption. 
VR adoption has not been studied and factors that drive its adoption are therefore unknown. It can be argued that AR is a similar context and previous studies chose to study the adoption of AR, revealing factors such as performance expectancy, effort expectancy, price value, personal innovativeness, pleasure, arousal and dominance to influence the behavioural intentions to use AR as travel guides (Kourouthanassis et al., 2015). Another study found quality, recommendations, costs, personal innovativeness, facilitating conditions and risk to influence the original TAM dimensions within the cultural tourism context (tom Dieck \& Jung, 2015). These examples show that adoption technology research is very much context-specific and that factors need to be explored on a case by case basis in order to ensure applicability for a chosen context (Ayeh et al., 2013). This has been confirmed by Kalantari (2017), who conducted a comprehensive literature review on consumers' adoption of wearable technologies and found influencing factors within the themes of perceived benefits, technology and individual characteristics, social factors and perceived risks. Kalantari (2017), similar to previous authors, reviewed theories on TAM, UTAUT, TPB, U\&GT and DIT and confirmed that no single theory is sufficient in order to fully evaluate the adoption of wearable technologies. Considering the limited research within the VR context, the present study aims to explore the factors driving the adoption within the VR tourism context, a field unexplored to the best of our knowledge.

\section{Methods}

\section{Study Context}

The study was conducted at a festival near Lake District National Park. Since the latter half of the twentieth century, festivals and events have become an increasingly important sector of the tourism and leisure industries (Getz, 2010; Chiang, Xu, Kim, Tang, \& Manthiou, 2017), and a growing area of interest within academic study. The study was conducted at the festival as the Lake District provided the VR experience to festival goers at a designated VR pavilion and aimed to explore if the experience influences peoples intention to visit the Lake District. Leisure visitors are attracted to National Parks because of the natural surrounding providing opportunity for myriad recreational activities, ranging from leisurely strolls to hiking on trails (Kamri \& Radam, 2013). The Lake District National Park has recently been recognised as a UNESCO World Heritage Site and aims to utilise latest technology in order to promote the region and gain national and international attention to increase tourist numbers. For this purpose, they developed a VR application of four areas of the Lake District in order to show potential tourists landscapes and natural offerings. The VR application used as part of this project offers potential tourists a bird view experience over the Lake District, incorporating natural sounds to create a tranquil experience. The application is ready to be downloaded on personal mobile devices and viewed using VR goggles from home but can also be viewed at the Lake District visitor centre. Therewith, it tries to attract new tourists and travellers as well as facilitate trip planning.

Please add Figure 1 here

\section{Data collection and analysis}


This exploratory study used exploratory semi-structured interviews in order to explore the adoption factors of VR within the national park context. Interview questions inquired about previous experience, usage, positive and negative feelings and aspects, overall impression, content, usability and attitude as well as future intentions. The population were festival goers and all adults above the age of 18 who visited a music festival near the Lake District in July 2016. Throughout the 3-day festival, more than 1000 adults tried the VR application and random sampling method was used to collect a sample for this exploratory study. According to Shenton (2004), random sampling increases the representativeness of a sample, as it includes the opinion of a general population rather than a selected sample. Interviews were conducted during one day of the festival and a total of 350 adult tried VR application. Every $10^{\text {th }}$ adult person who tried the application on the day was approached and asked to participate in the study. A total of 35 interviews were conducted ranging from 10 to 18 minutes in length. Interviewees were aged from 18 to 58. Eight participants had previous VR experience and the majority has visited the Lake District National Park previously (see Table 1). The interviews were analysed using thematic analysis. Thematic analysis is an appropriate technique to code interview transcripts according to adoption factors and relevant sub-themes (Alholjailan, 2012). Within the analysis, participants are referred to as P1-P35 (see Table 1). Researchers thoroughly reviewed previous literature in order to identify relevant themes (e.g. usability) and sub-themes (e.g. perceived ease of use). The researchers then developed codes based on these previously identified themes and sub-themes in order to generate a thematic map (Boyatzis, 1998). Afterwards, the researchers analysed the transcripts to identify existing themes and sub-themes and to generate emerging themes and sub-themes (tom Dieck \& Jung, 2017).

\section{Please add Table 1 here}

\section{Findings}

The findings are presented as main themes and relevant sub-themes which represent adoption factors.

\section{Usability}

Perceived ease of use

According to the majority of participants, the VR application was perceived to be uncomplicated, the headset comfortable, the sound clear, and the visual engaging, thus, resulting in a seamless ease of use. Only few participants (P1, P7, P11 and P32) found that it was difficult to adjust the screen to the right focus in order to have an optimal experience. On the contrary P31 revealed 'the app was very easy to use [and] adjusting the focus was easy', confirming majority's opinion that well-designed VR apps allow for an easy user experience. Overall, participants confirmed that they did not find it difficult to use the application, ensuring a high perceived ease of use.

\section{Comfort}


The vast majority of participants found the VR application to be comfortable to use. This is particularly true with regards to the comfort of using the application rather than the device. For instance, P7 mentioned 'the app was perfect length of time, any longer, I would have got motion sickness'. A similar comment was made by P5, who usually gets travelsick but experienced a very comfortable five minutes experiencing the Lake District.

\section{Personalisation}

Personalisation is an important aspect of technology design which was also shown in this study. While some participants preferred to have less sound (P9), others found it the perfect mix (P6, P26, P32, P35), while some wished for a more diverse range of noises to make it more realistic $(\mathrm{P} 1, \mathrm{P} 3, \mathrm{P} 4, \mathrm{P} 5)$. Contradicting opinions can be found from the following examples. While P9 stated 'I presume it is quiet that high up', P5 assumed 'there is a lot of wind noise that high up' and P26 'enjoyed the sound and would not expect to hear anything else'. In addition, content-wise, participants (P1, P4) felt that a personalised tour would enhance the experience as there should not be a one-fits-all approach to application design. In fact, different interests (e.g. hiking, sailing etc.) influence which parts of the Lake District visitors want to virtually experience. This shows that a personalised approach to app development would enhance the individual experience, which was thoroughly discussed in previous adoption literature (tom Dieck et al., 2016).

\section{Perceived control}

The ability to explore a 360-degree view was particularly captivating as it was 'interactive, stimulating and exciting', and allowed the user to feel in control of their own, personal experience. The majority of participants therefore agreed that they felt completely in control of their virtual experience. According to P19 'it was good to be in control where you can look around in 360 view, which makes it different from just watching a video on TV where you are not in control'. Interestingly, P20 revealed that 'lack of control might be an issue' with the application, clearly showing dividing opinions regarding this as the flight path of the drone was obviously fixed and user control only extended as far as to which direction participants could look in. Nevertheless, it also shows that perceived control is an important factor for VR adoption.

\section{Hedonic benefits}

\section{Enjoyment}

Enjoyment has been one of the key factors throughout interviews and the majority of participants (except P17 and P29) confirmed that they felt the application to be 'fun to use', 'enjoyable', 'stimulating and exciting' or 'amazing'. P3 for instance found the experience 'brilliant, fun to use [and] enjoyed the fact that [he] was completely captivated'. Interestingly, some participants claimed to be 'surprised' and 'impressed' to learn that the destination had such a vast number of striking locations, whilst others were reminded of the destination's appeal (P1-P5, P12). Considering that enjoyment has been regularly included in latest technology adoption research (e.g. Rauschnabel et al., 2017; 
Tussyadiah et al., 2017) this comes as no surprise and supports the construct within the VR tourism context.

\section{Experienced realism}

Hoffman (1998) was among the first to explore that the ability to touch "virtual" objects adds to the sense of experienced realism. Within the present study, the majority of participants experienced some sense of realism during the VR experience, stating that the bird's eye view instigated a sense of freedom and positive detachment from reality. According to P8, 'the Lake District National Park was the reality for me from start to finish'. P29 confirmed that she 'was completely lost in the experience [and] lost in the moment'. The combination of the sound and visual collectively contributed to a number of participants feeling a sense of 'complete captivation' into the virtual world. More specifically, P20 revealed 'the sound helped me to feel like I was high in the sky, without the sound, I would still feel like I was here at the festival'. Finally, according to P10, 'I had to hold on to the chair because it did feel so realistic'. However, some participants (P10, P15, P27) claimed that certain visual aspects such as being as high as the trees and close to the water, influenced a sense of feeling 'uneasy, sick and dizzy'. In addition, those whom did not experience full immersion into the virtual world, suggested noise cancelling headphones, and a quieter location with fewer distractions (P9, P18). Overall, the vast majority of participants were fully immersed by the virtual experience, and subsequently detached from the real-world environment. For instance, P15 felt 'the VR experience removes me from the real world as it is very immersive'. In addition, the feeling of movement was effective in stimulating senses such as a jolt of adrenaline, which positively contributed to the fully immersive experience.

\section{Personal benefits}

Perceived usefulness

Well known from TAM (Davis, 1989), perceived usefulness is a personal factor that emerged from the interviews with every single participant confirming that VR is useful to create awareness of the Lake District as a tourist destination. Furthermore, the VR experience was considered extremely useful in educating tourists about locations within the Lake District. According to P12, the VR experience 'is good at creating awareness of the Lakes, and introducing new tourists to the beautiful scenery... in a more interactive way... as opposed to looking online or in a brochure'. This shows that the VR application helped in the creation of knowledge and collection of information (P18, P22). In terms of technology acceptance research, this can be considered to enhance the effectiveness in travel planning as well as make the entire experience more convenient (Kim et al., 2008).

\section{Emotional benefits}

Place attachment

Place attachment has recently received attention within the AR context and refers to people's memories and the creation of meaningful bonds with places (Oleksy \& Wnuk, 2017). According to Pantelidis et al. (2018, p. 2), "individuals create meaningful bonds with places. This bonding is an essential experience and ties people to social and physical environments, linking them to the past and influencing the future behaviour". One 
participant who found the VR experience linked to place attachment was P10 stating 'I have not been to the Lakes before so it was good to see the different areas, and some parts reminded me of places in Ireland where I have family'. Interestingly, also P8 revealed that the application 'triggered memories of the locations', clearly linking it to the concept of place attachment as memories of past experiences seem to influence future visit behaviours.

\section{Attitude}

Overall, the attitude towards using such a VR application to experience destinations has been positive by the majority of participants. For P15, 'the VR experience changed my perspective of things and was good fun'. The element of 'fun' led two participants (P11, P15) to suggest a similar experience 'would be good for children to experience destinations that they have never been to in the headset, to better understand what [various destinations] are like' (P11). Other favourable attitudes towards the VR experience included feeling 'completely relaxed' (P4, P22, P33), 'completely captivated' (P3), and the unique feature of this particular experience i.e. 'the birds eye view' was positively received by several participants $(\mathrm{P} 2, \mathrm{P} 8, \mathrm{P} 32, \mathrm{P} 35)$ as this perspective is 'something that is not available otherwise' (P2).

Negative attitude has been limited. Only P7 was hesitant and held a slightly negative attitude after experiencing the application and revealing ' $I$ would not feel comfortable with prolonged use', while P6 mentioned that the app should be 'more educational'. There were a few other mentions of aspects that could be considered negative although they were encased in positive connotations. P23 stated, 'I enjoyed being lost in the experience, however, I felt out of control, which made me feel slightly odd', and P15 felt 'totally immersed and slightly dizzy'. While P20 suggested that 'people with accessibility issues would benefit from the experience, although lack of control may be a problem... [the VR experience] could frighten people or make them dizzy, but having someone assisting with the experience would help to overcome this'. These last few statements are initially spun in a positive way although they follow up with some 'feelings' or 'aspects' that experiences from mobile app development might recommend should be taken as a sign of warning. Generally, the terms 'odd', 'slightly dizzy' or 'lack of control' should be considered as negative outside the realm of experiences that are specifically designed to be so; which this demonstration was not.

\section{Behavioural intentions}

\section{Intention to use}

The intention to reuse such an application when coming to the Lake District was confirmed by all participants which indicates a good degree of acceptance of VR as a vehicle to market and promote destinations. Several participants (P4, P5, P12, P16, P20, $\mathrm{P} 32$, P33) furthermore confirmed that they would like to experience VR for other destinations in order to make an informed decision before visiting. For example, P11 stated 'it is a good way to look at a destination you might never have been before prior to visiting, and from a different perspective', and P5, 'I would like to see similar destinations in VR ...I think it would be a good way to attract people to a destination, rather than use at a destination'. 


\section{Intention to visit}

The importance for marketing destinations and create intentions to visit was also discussed as part of the interviews. For instance, P20 revealed 'I would love to repeat the experience again. I would love to experience New York with the skyscrapers because I was too scared to do the helicopter ride there and it is much better than looking at a picture in a brochure'. In addition, 'with other destinations, it would be a good way to plan where you want to go and what to visit' (P4). Finally, P33 stated 'it would work with travel agents, to experience holiday destinations beforehand to see exactly where you are going'. From these findings it becomes apparent, that such as application is not only considered a positive step for the Lake District but destinations in general. Overall, every single participant revealed that such an application influences the intention to visit, if, done professionally and in good quality.

\section{Intention to recommend}

A large number of participants specifically talked about their desire to recommend the experienced VR applications to others, mostly talking about friends and family (P1, P3, P4, P6, P8, P10, P13, P16, P17, P20, P21, P23, P24, P29, P30, P33). According to P13, 'I would recommend the experience to others to think about where to go in the Lakes and to open them up to the knowledge of the destination'. In addition, an interesting statement was made by P17 who would 'recommend the app to others for relaxation'.

\section{Motivational change}

The final behavioural intention element is the 'motivation' to do things differently. As identified by $\mathrm{P} 2$, who revealed 'it has motivated me to want to fly through the Lake District in a helicopter and have a different experience than what I usually do'. Also, P20 said that attitude about the Lake District changed and it motivated her to visit different areas of the destination. Seeing VR as a motivation tool within tourism was also suggested by P22 P27 and P32.

\section{Please add Figure 2 here}

\section{Discussion and Conclusion}

The aim of this study was to answer the following two research questions: 1 . Which factors drive tourists' VR adoption within the national park context? and 2. How is VR influencing tourists' behavioural intentions within the national park context? Using an exploratory approach, the study explored previous technology adoption literature and revealed a number of theories and studies on technology adoption that each identified context-specific adoption factors (e.g. Kalantari, 2017; Rauschnabel et al., 2017; tom Dieck and Jung, 2015).

With regards to research question 1 , the present study found a number of factors that influence tourists' adoption of VR within the national park context which can be categorised under usability, hedonic benefits, emotional benefits, social benefits, attitude and behavioural intention. Some of the identified factors such as perceived usefulness and perceived ease of use from the TAM mirror a large number of studies (e.g. Ayeh et al., 2013; Davis, 1989) within various contexts and are therefore unsurprisingly found to 
influence VR adoption. Other factors such as place attachment are more unique within technology adoption literature and only received limited attention from previous researchers (Kim et al., 2016; Turan et al., 2015). Considering the importance of comfort discussed within AR literature (Kalantari, 2017), VR applications also have to consider the comfort factor in order to increase adoption. It is important to recognise that while conclusions to the degree of comfort might be drawn from these interviews, they can only be generalised to the use of 'this' VR application's use, and not all VR application use in general. There might be some further study implications of interest which are generalisable to all VR applications; Certain key takeaways could be used of the specific device set up (Samsung Gear VR/Galaxy S7 Mobile Phone), which did not cause the experience to be uncomfortable. However, this is of little use for further VR experience design as it was not evaluated whether this is the best set up. As such, for the context of this study, the comfort aspect is in relation to the specific set up of hard and software of this experiment. Finally, experienced realism appeared as part of VR research (e.g. Ling et al., 2013) however, has not been incorporated in adoption research or models. This demonstrates the importance of exploring context-specific factors in order to account for characteristics and features of single technologies and cases.

With regards to the second research question, the majority of previous research and theories looked into behavioural intentions and actual usage behaviour in order to assess users' decision to accept or reject certain technologies and innovations (Davis, 1089; Fishbein and Ajzen, 1975). However, as part of tourism research and web 2.0 developments, behavioural intentions are expected to be much broader and the intention to recommend, spread positive word-of-mouth and return to a destination are immensely important. This was echoed in previous tourism literature (Manthoi et al., 2014; Tasci, 2016; tom Dieck et al., 2017). To answer the second research question, this study found that VR influences tourists' intention to use the application, visit the Lake District in the future, recommend it to family and friends, motivational change as well as intention to revisit in the future (loyalty). The majority of participants of this study had previous been to the Lake District, however those who have not, indicated that the VR application would influence their desire to visit which shows the power of VR for marketing of destinations, an area that only received limited research to date. In addition, participants indicated that such an application would entice them to visit other destinations leading to VR as a powerful tool to attract new tourists. However, one aspect that could not be explored was whether and to what degree the VR experience triggered some kind of "novelty factor". A chance remains that participant's interest/curiosity in the first time VR experience superseded their expression of a genuine deep rooted interest/enjoyment of the VR application. As such this matter requires further investigation. Some destinations such as the Lake District started to implement VR into their marketing campaigns and from the findings of this study it can be suggested that VR appears to be one of the ways forward to create marketing campaigns. However, personalisation has been an important aspect within marketing and tourism literature (Berezan et al., 2016) and the present study supported the need to create targeted applications for various markets with the opportunity to tailor applications to the wants and needs of individual users. This is cost intensive, and considering that many destinations just startet to explore the opportunities, personalisation could be seen as a second step once VR is fully adopted.

\section{Theoretical contributions and managerial implications}


Theoretical contributions of this study are twofold. First, technology adoption has been well discussed and researched within various contexts, more recently with a vast amount of studies on AR (e.g. Kalantari, 2017; Rauschnabel et al., 2017; tom Dieck \& Jung, 2015; Tussyadiah ety al., 2017). However, studies that explore factors that drive tourists' VR adoption within the tourism and especially outdoor national park context have been limited and the present study proposed a context-specific model with VR adoption factors. For instance, the majority of factors explored within this study have previously been used as part of technology acceptance research. Nevertheless, factors such as experienced realism and place attachment are relatively new with limited previous evidence of influence on technology adoption. This represents an important theoretical contribution of this study.

Second, this study aimed to explore how VR is influencing tourists' behavioural intentions within the national park context. Exploring different dimensions how VR effects tourists behavioural intentions provides important areas for future technology adoption research with regards to dependent variables. One of the most interesting contributions is the finding of motivational change. Previous research commonly found intention to recommend or use as a behavioural intention (e.g. Kim et al., 2008) however, motivational change is unexplored to the best of our knowledge. Motivational change is believed to be linked to the power of disruptive VR experiences which show the existing world in a new light. Especially in this case study, users experienced an environment from a completely new angle; giving them a new motivation to visit and explore the Lake District. It is expected that technology in general will increasingly do so and therefore, motivational change is a new consideration of technology adoption literature in the future.

Tourism destinations and destination management organisations can benefit from the findings of this study as it is one of the first qualitative investigations of tourists' VR adoption behaviour in the context of national park. Factors that drive VR adoption were explored and destinations and application developers can utilise this knowledge to develop and implement VR accordingly. In addition, the study supported a general acceptance of VR, specifically for marketing purposes and well as tour guide for potential tourists. Considering the highly competitive nature of today's tourism industry, this study suggests that VR can be used as an important vehicle in the early stages of tourist acquisitions in order to attract new markets or as a tool to enhance the pre-trip experience. In fact, at destinations such as the Lake District National Park, authorities could offer such applications at visitor centres or at tourist information points in order to allow tourists to plan or prioritise trips. Overall, this study provides destinations with a theoretical model as to how VR applications should be designed and which content should be considered in order to be implemented successfully.

\section{Limitations and future research}

As with any research, this study has some limitations. First, the data was collected at one point in time with participants who visited a festival close to the Lake District National Park. Therefore, the majority of the sample turned out to be knowledgeable of the area and probably biased with regards to revisit intentions. Nevertheless, considering that the study focused on VR adoption, most participants tried VR for the first time and had therefore an open mind with regards to the capabilities for tourism. On the flipside, as indicated in the discussion section this could have meant that participant's reactions to 
the VR experience were influenced by the novelty of the experience itself rather than the VR content. As such when it comes to "intention to use" the study might paint a skewed picture. Second, the qualitative nature of this study enabled to identify new and contextspecific factors of VR adoption. However, findings are therefore not generalisable and need to be tested on a bigger sample. Third, testing the model in another context would help to understand its power in explaining adoption behaviours across multiple settings.

\section{References}

Ajzen, I. (1985). From intentions to actions: A theory of planned behavior. In Action control (pp. 11-39). Berlin: Springer.

Alholjailan, M.I. (2012). Thematic Analysis: A critical review of its process and evaluation. West East Journal of Social Sciences, 1(1), 39-47.

Ayeh, J. K., Au, N., \& Law, R. (2013). Towards an understanding of online travellers' acceptance of consumer-generated media for travel planning: Integrating technology acceptance and source credibility factors. In Information and Communication Technologies in Tourism 2013 (pp. 254-267). Berlin: Springer.

Berezan, O., Yoo, M., \& Christodoulidou, N. (2016). The impact of communication channels on communication style and information quality for hotel loyalty programs. Journal of Hospitality and Tourism Technology, 7(1), 100-116.

Boyatzis, R. (1998). Thematic analysis and code development - transforming qualitative information. Thousand Oaks: Sage.

Chiang, L., Xu, A., Kim, J., Tang, L., \& Manthiou, A. (2017). Investigating festivals and events as social gatherings: the application of social identity theory. Journal of Travel \& Tourism Marketing, 34(6), 779-792.

Chung, N., Han, H., \& Joun, Y. (2015). Tourists' intention to visit a destination: The role of augmented reality (AR) application for a heritage site. Computers in Human Behavior, 50, 588-599.

Davis, F. D. (1989). Perceived usefulness, perceived ease of use, and user acceptance of information technology. MIS quarterly, 319-340.

Disztinger, P., Schlogl, S., \& Groth, A. (2017). Technology acceptance of virtual reality for travel planning. In R. Schegg \& B. Stangl (Eds), Information and Communication Technologies in Tourism 2017 (pp. 255-268). Berlin: Springer.

Fishbein, M., \& Ajzen, I. (1975). Belief, attitude, intention and behavior: An introduction to research and theory. Reading: Addison-Wesley.

Getz, D. (2010). The nature and scope of festival studies. International Journal of Event Management Research, 5(2), 1-47.

Griffin, T., Giberson, J., Lee, S.H., Guttentag, D., \& Kandaurova, M. (2017). Virtual reality and implications for destination marketing. Tourism Travel and Research Association: Advancing Tourism Research Globally. 29.

Guttentag, D.A. (2010). Virtual reality: Applications and implications for tourism. Tourism Management, 31, 637-651.

Hassan, A., Ekiz, E., Dadwal, S. \& Lancaster, G. (2017). Augmented Reality Adoption by Tourism Product and Service Consumers: Some Empirical Findings. In T. Jung \& M.C. tom Dieck (Eds.), Augmented Reality and Virtual Reality: Empowering Human, Place and Business, Heidelberg: Springer.

Hobson, J.S.P., \& Williams, A.P. (1995). Virtual reality: A new horizon for the tourism industry. Journal of Vacation Marketing. 1(2), 124-135. 
Hoffman, H. G. (1998). Physically touching virtual objects using tactile augmentation enhances the realism of virtual environments. In Virtual Reality Annual International Symposium, (pp. 59-63). IEEE.

Huang, Y., Backman, K., Backman, S., \& Chang, L. (2016). Exploring the implications of virtual reality technology in tourism marketing: An integrated research framework. International Journal of Tourism Research. 18, 116-128.

Huang, Y., Backman, S., Backman, K., \& Moore, D. (2013). Exploring user acceptance of 3D virtual worlds in travel and tourism marketing. Tourism Management. 36, 490501 .

Jung, T., Kim, M., \& Leue, M.C. (2014). Acceptance of GPS-based Augmented Reality Tourism Applications. Paper presented at EuroCHRIE conference, October, Manchester, UK.

Jung, T. tom Dieck, M.C., Moorhouse, N. \& tom Dieck, D. (2017). Tourists experience of virtual reality applications. IEEE International Conference on Consumer Electronics, Las Vegas.

Kalantari, M. (2017). Consumers' Adoption of Wearable Technologies: Literature Review, Synthesis, and Future Research Agenda, International Journal of Technology Marketing, forthcoming.

Kalantari, M. \& Rauschnabel, P.A. (2017). Exploring the Early Adopters of Augmented Reality Smart Glasses: The Case of Microsoft HoloLens. In T. Jung \& M.C. tom Dieck (Eds.), Augmented Reality and Virtual Reality: Empowering Human, Place and Business (pp. 249-255), Berlin: Springer.

Kamri, T., \& Radam, A. (2013). Visitors' visiting motivation: Bako National Park, Sarawak. Procedia Social and Behavioral Sciences, 101, 496-505.

Kourouthanassis, P., Boletsis, C., Bardaki, C., \& Chasanidou, D. (2015). Tourists responses to mobile augmented reality travel guides: The role of emotions on adoption behavior. Pervasive and Mobile Computing, 18, 71-87.

Kim, M. J., Kim, W. G., Kim, J. M., \& Kim, C. (2016). Does knowledge matter to seniors' usage of mobile devices? Focusing on motivation and attachment. International Journal of Contemporary Hospitality Management, 28(8), 1702-1727.

Kim, D. Y., Park, J., \& Morrison, A. M. (2008). A model of traveller acceptance of mobile technology. International Journal of Tourism Research, 10(5), 393-407.

Ling, Y., Nefs, H. T., Brinkman, W. P., Qu, C., \& Heynderickx, I. (2013). The relationship between individual characteristics and experienced presence. Computers in Human Behavior, 29(4), 1519-1530.

Manthiou, A., Lee, S., Tang, L., \& Chiang, L. (2014). The experience economy approach to festival marketing: Vivid memory and attendee loyalty. Journal of Services Marketing, 28(1), 22-35.

Martins, J., Goncalves, R., Branco, F., Barbosa, L., \& Melo, M. (2017). A multisensory virtual experience model for thematic tourism: A port wine tourism application proposal. Journal of Destination Marketing \& Management. 6, 103-109.

Narangajavana, Y., Fiol, L. J. C., Tena, M. Á. M., Artola, R. M. R., \& García, J. S. (2017). The influence of social media in creating expectations. An empirical study for a tourist destination. Annals of Tourism Research, 65, 60-70.

Niu, Y., Wang, C. L., Yin, S., \& Niu, Y. (2016). How do Destination Management Organization-Led Postings Facilitate Word-of-Mouth Communications in Online Tourist Communities? A Content Analysis of China's 5A-Class Tourist Resort Websites. Journal of Travel \& Tourism Marketing, 33(7), 929-948. 
Oleksy, T., \& Wnuk, A. (2017). Catch them all and increase your place attachment! The role of location-based augmented reality games in changing people-place relations. Computers in Human Behavior (76), 3-8.

Pantelidis, C., tom Diek, M. C., Jung, T., \& Miller, A. (2018). Exploring Tourist Experiences of Virtual Reality in a Rural Destination: A Place Attachment Theory Perspective. e-Review of Tourism Research. 1-5.

Rauschnabel, P. A., \& Ro, Y. K. (2016). Augmented reality smart glasses: An investigation of technology acceptance drivers. International Journal of Technology Marketing, 11(2), 123-148.

Rauschnabel, P. A., Rossmann, A., \& tom Dieck, M. C. (2017). An Adoption Framework for Mobile Augmented Reality Games: The Case of Pokémon Go. Computers in Human Behavior, 76, 276-286.

Rogers, E. M. (1962). Diffusion of innovations. New York: Free Press.

Shenton, A. K. (2004). Strategies for ensuring trustworthiness in qualitative research projects. Education for information, 22(2), 63-75.

Tasci, A. D. (2016). A quest for destination loyalty by profiling loyal travelers. Journal of Destination Marketing \& Management. Doi.org/10.1016/j.jdmm.2016.04.001

tom Dieck, M. C., Fountoulaki, P., \& Jung, T. H. (2018). Tourism distribution channels in European island destinations. International Journal of Contemporary Hospitality Management, 30(1), 326-342.

tom Dieck, M. C., \& Jung, T. H. (2017). Value of augmented reality at cultural heritage sites: A stakeholder approach. Journal of Destination Marketing \& Management, 6(2), 110-117.

tom Dieck, M. C., \& Jung, T. (2015). A theoretical model of mobile augmented reality acceptance in urban heritage tourism. Current Issues in Tourism, 1-21.

tom Dieck, M. C., Jung, T. H., Kim, W. G., \& Moon, Y. (2017). Hotel guests' social media acceptance in luxury hotels. International Journal of Contemporary Hospitality Management, 29(1), 530-550.

Turan, A., Tunç, A. Ö., \& Zehir, C. (2015). A theoretical model proposal: Personal innovativeness and user involvement as antecedents of unified theory of acceptance and use of technology. Procedia-Social and Behavioral Sciences, 210, 43-51.

Tussyadiah, I. P., Jung, T. H., \& tom Dieck, M. C. (2017a). Embodiment of Wearable Augmented Reality Technology in Tourism Experiences. Journal of Travel Research, 0047287517709090.

Tussyadiah, I.P., Wang, D., \& Jia, C. (2016). Exploring the persuasive power of virtual reality imagery of destination marketing. Tourism Travel and Research Association: Advancing Tourism Research Globally. 25.

Tussyadiah, I.P., Wang, D., \& Jia, C.H. (2017b). Virtual reality and attitudes toward tourism destinations. In R. Schegg \& B. Stangl (Eds), Information and Communication Technologies in Tourism 2017 (pp. 255-268). Heidelberg: Springer.

Whyte, P. (2016). VR offers hope to high street. Travel Trade Gazette UK \& Ireland, 2829.

Zorn, S. F., Lee, R. Y., \& Murphy, J. (2012). Marketing implications of traditional and ICT-mediated leisure activities. Behaviour \& Information Technology, 31(4), 329341. 